available, hypotheses multiply, each able to explain the observations. The contribution of such empirical analyses to the search for the causes of climatic changes can be maximised if they are used in conjunction with the theoretical approach to the same problem: numerical modelling. The numerical modelling of climatic change and the general circulation of the atmosphere is at an early stage of development; such experiments are primarily designed to test the behaviour of the models, using unrealistically large anomalies in the boundary conditions to produce an unequivocal response in the atmosphere. Until reliable coupled ocean-atmosphere models become available, numerical models can only provide a static picture of a climatic state and cannot portray climatic evolution. Their potential, however, is great and slowly being realised. Hypotheses concerning the causes of climatic change based on empirical evidence can be tested by numerical simulation and vice versa.

To assess the relative importance of the climatic controls, it is necessary to specify realistic anomalies in the boundary conditions of the models. Otherwise the value of the experiment is lessened. It may indicate that a particular control can be effective, but not how effective. The use of information concerning actual changes in the boundary conditions of the atmosphere, such as contained in the article by Colebrook, should ensure that the results of numerical modelling experiments do not diverge unnecessarily from reality.

Increased collaboration between people studying climatic change within a theoretical framework and those concentrating on the observational data is highly desirable, and perhaps essential if climatology is to provide some indication of future $\mathrm{climatic}$ development.

\section{Chinese mitten crab reappears in Britain}

from R. W. Ingle and M. J. Andrews

THE unintentional transportation of animals by man beyond the range of their normal habitats has always interested zoogeographers. Five species of true crabs have arrived in British waters in this manner. One of these, the Chinese mitten crab, is of particular interest as its spread through Europe since its introduction from China has been well documented and because it has now reappeared in Britain after an

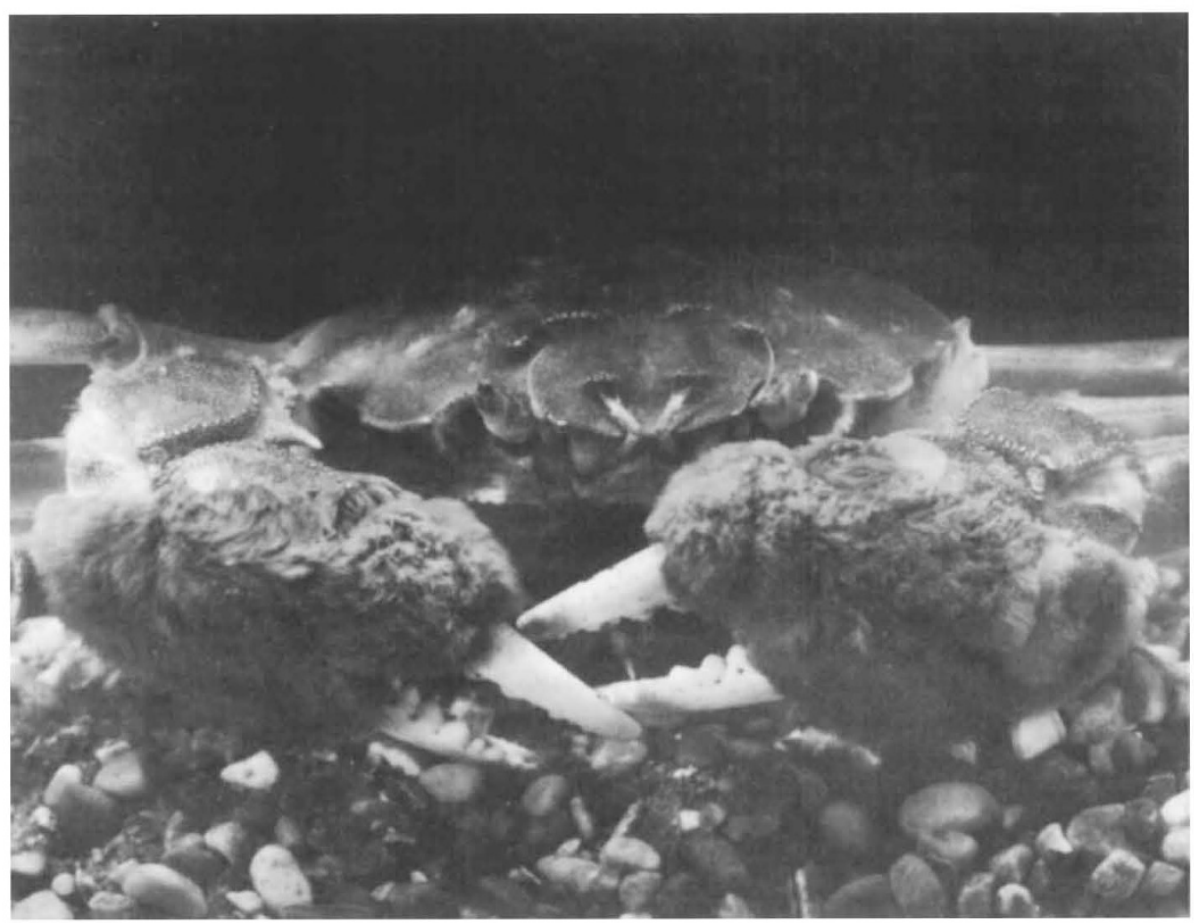

Front view of the male mitten crab from West Thurrock generating station. This species is easily recognised by the dense fur on the claws. The body colour varies from greenish grey to dark brown.

apparent absence of some $27 \mathrm{yr}$.

The mitten crab, Eriocheir sinensis A. Milne Edwards, is a native of temperate eastern Asia and occurs from the Fukien province of China to the western coastal region of Korea. In Korea it shows preference for rice fields near the coast and inland occurs only in rivers. Life in this temperate environment has enabled the crab to adapt to similar climatic conditions in northern Europe from where it was first reported in 1912 from the Weser River near Retham, Germany and later from other parts of the country. In the 1920 s the crab spread rapidly westward and was recorded from rivers in the Netherlands, Belgium, France, Denmark and Finland. Its occurrence in Britain was first reported in 1935 when a male was found in the River Thames at Chelsea, then in 1949 a second specimen was discovered in Southfields reservoir near Castleford, Yorkshire. There have been no other reports of this crab in Britain until this year when three specimens were taken from the cooling water intake screens of West Thurrock electricity generating station in February, May and June. The West Thurrock station is situated in a brackish region of the River Thames estuary $36 \mathrm{~km}$ below London Bridge where the average half-tide salinity for the first half of 1976 was approximately $20 \mathrm{~g}$ per $1,000 \mathrm{~g}$.

The mitten crab probably reached Europe in the ballasting tanks of commercial vessels, having entered the tanks in Chinese waters as free swimming larvae and developed en route to be liberated as juveniles when the tanks were emptied in Germany. Studies in Europe have shown that adult crabs prefer freshwater and live in rivers but migrate into estuaries to breed. The eggs are hatched in brackish water and developing larvae move gradually back into freshwater.

This recent reappearance of the mitten crab in the Thames is interesting because all the specimens were found within a period of 5 months and in an area that has been surveyed regularly since the 1960 s, during which time the crab was never reported. It is probable that these individual crabs were transported to the West Thurrock region by ships arriving from European ports (more than 100 ships from Antwerp and Rotterdam have visited West Thurrock in the past $2 \mathrm{yr}$ ), and does not constitute a serious invasion by the species. In large numbers mitten crabs can cause considerable damage to estuarine river banks resulting from the subsidence of their numerous small burrows in the mud. The crab is also reported to cause damage to fishing nets by cutting the mesh in which they often become entangled. There seems no obvious reason why Eriocheir should not become established in the British Isles and the arrival of females carrying eggs would be a significant step towards this invasion; further occurrences of the mitten crab are awaited with interest. 